\title{
Synthesis, Structure, and Thermal Properties of Widely-Spaced Comb-Like Polymers
}

\author{
Kenji YoKota, Takanori Kougo, and Tadamichi HiRABAYASHI \\ Materials Research Laboratory, Nagoya Institute of Technology, \\ Gokiso-cho, Showa-ku, Nagoya 466, Japan
}

(Received August 10, 1983)

\begin{abstract}
Alternating copolymers of butadiene and long alkyl methacrylates I and their hydrogenated copolymers II were synthesized, characterized and designated as widely-spaced comblike polymers.<smiles>CC=CCCC(C)C(=O)OCCCCCCCC(=O)OCc1ccccc1</smiles>

$n=12,14,16$, and 18

A differential scanning calorimetry study of these copolymers indicated that their alkyl side chains could crystallize in the same order as those of poly(alkyl methacrylates).

KEY WORDS Comb-Like Polymer / Widely-Spaced Comb-Like Polymer /

Butadiene / Methacrylate / Long Alkyl Group / Alternating Copolymer /

Hydrogenation / Differential Scanning Calorimetry / Crystallization
\end{abstract}

Macromolecules whose repeating units have long side chains (generally an alkyl group) are denoted as comb-like polymers ${ }^{1}$ and have been intensively studied in recent years owing to their intermediate place between linear and branched polymers. ${ }^{2}$<smiles>[H][Y]([H])([H])[CH]C</smiles>

These comb-like polymers are known to crystallize through alkyl side chain packing independently of the stereoregularity of the main chain. This was first recognized by Greenberg and Alfrey ${ }^{3}$ who reported the ability of atactic poly(alkyl acrylates) and poly(alkyl methacrylates) to form crystalline phases made up of alkyl side chains rather than main chains. So far, such macromolecules as poly(1alkenes) ${ }^{4}$ poly(alkyl vinyl ethers), ${ }^{5}$ poly(vinyl alkanoates), ${ }^{6}$ poly(alkylstyrenes), ${ }^{7}$ have been studied.

This paper deals with the synthesis, structural characterization and a differential scanning calorimetry study of alternating butadiene-long alkyl methacrylate copolymers I and their hydrogenated copolymers II.
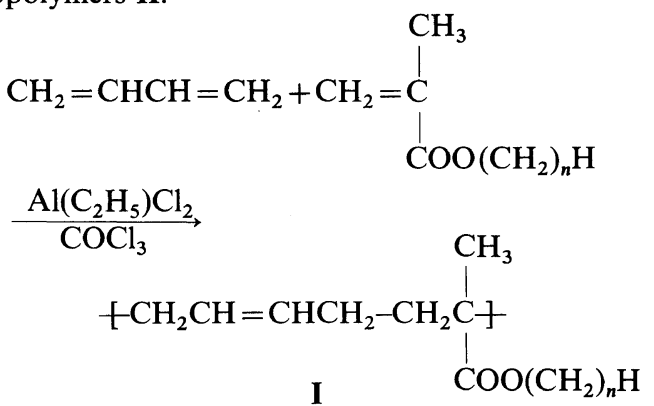


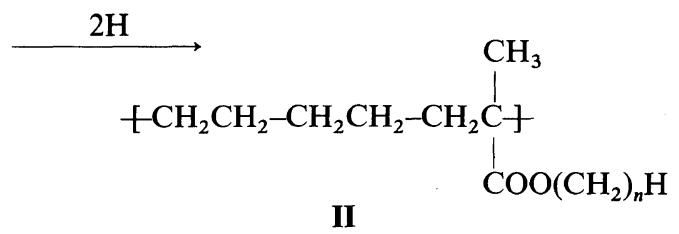

In these copolymers, the long alkyl side chains appear on every six main chain carbon atoms and therefore are designated as widely-spaced comb-like polymers (Figure 1). Our interest was directed to finding out whether these widely-spaced side chains, with intervening seven carbon atoms, crystallize.

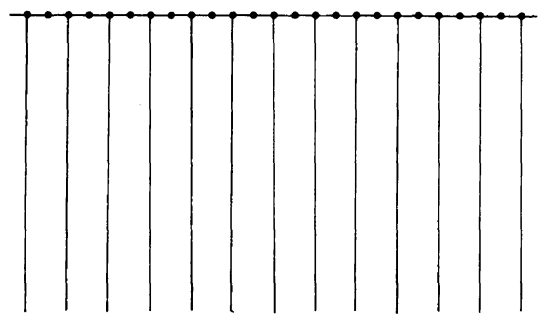

(a) Conventional comb-like polymer

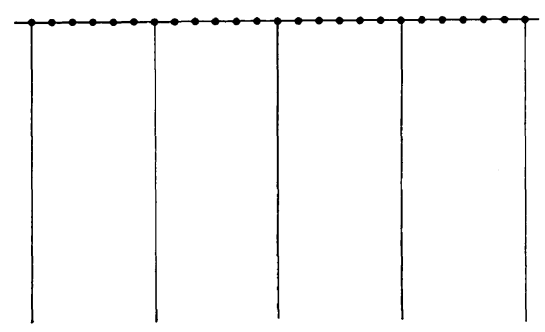

(b) Widely-spaced comb-like polymer

Figure 1. Schematic diagrams of (a) conventional and (b) widely-spaced comb-like polymers.

Overberger et al. ${ }^{8}$ studied the glass-transition temperature of poly(2-alkyl-1,3-butadienes) in an attempt to improve the low temperature flexibility of these rubbers. In this series of polymers, alkyl side chains appear on every four carbon atoms. Because the alkyl groups studied were not long enough (heptyl and decyl), they could observe only the glass-transition but not melting temperatures.

\section{EXPERIMENTAL}

\section{Monomers}

Butadiene extra pure grade was commercially obtained. Alkyl methacrylates were prepared by the alcoholysis of methyl methacrylate with higher alkanols in the presence of $p$-toluenesulfonic acid as the catalyst and a trace amount of hydroquinone as the inhibitor. They were purified by distillation under vacuum in the presence of the inhibitor, and characterized by their boiling points, infrared (IR) and ${ }^{1} \mathrm{H}$ nuclear magnetic resonance (NMR) spectra. Dodecyl, tetradecyl, hexadecyl, and octadecyl methacrylates were synthesized.

\section{Other Reagents}

Ethylaluminum dichloride from Ethyl Corp. was distilled under vacuum and dissolved in toluene $(50 \mathrm{vol} \%)$. Extra pure vanadyl chloride was dissolved in hexane as received $\left(0.25 \mathrm{~mol} \mathrm{dm}^{-3}\right)$. Extra pure $p$-toluenesulfonylhydrazide was recrystallized from ethanol.

\section{Polymerization}

The synthesis of alternating butadiene-alkyl methacrylate copolymers was carried out essentially by the method in our previous paper using the hydrogenated alternating butadiene-methyl methacrylate copolymer. ${ }^{9}$ A mixture of butadiene, an alkyl methacrylate, the ethylaluminum dichloride solution (equimolar to alkyl methacrylate), and the vanadyl chloride solution (1/40 molar to ethylaluminum dichloride) in a test tube was occasionally shaken for several hours until it solidified in an icewater bath. The mixture was then poured into methanol containing $1 \mathrm{vol} \%$ of concentrated hydrochloric acid to precipitate the alternating copolymer I. It was purified by repeated reprecipitations from the benzene solution into acetone. Poly(alkyl methacrylates) (homopolymers III) were obtained for comparison by warming alkyl methacrylate monomers in equivolume toluene with $\alpha, \alpha^{\prime}$-azobisisobutyronitrile $(1 \mathrm{~mol} \%)$ at $60^{\circ} \mathrm{C}$.<smiles>CC(C)C(=O)OCc1ccccc1</smiles>

III

\section{Hydrogenation}

Platinum black-catalyzed hydrogenation, by either atmospheric or high pressure hydrogen, was very slow for long alkyl side chain copoly- 
mers I. Hydrogenation by $p$-toluenesulfonylhydrazide $^{10}$ gave good results. To a refluxing toluene solution of a copolymer $\mathbf{I}, 2$ equivalents of $p$ toluenesulfonylhydrazide were added portionwise. After $5 \mathrm{~h}$ refluxing, the solution was poured into a large volume of methanol to precipitate the hydrogenated copolymer II. The residual unsaturation in the copolymer was checked by ${ }^{1} \mathrm{H}$ NMR spectrum and was again reacted with 2 equivalents of the reagent to complete the hydrogenation. The copolymer yield was almost quantitative.

\section{Measurement}

IR spectra were recorded on a JASCO IR-E spectrometer. ${ }^{1} \mathrm{H}$ and ${ }^{13} \mathrm{C}$ NMR spectra were taken on a Hitachi R-20B operating at $60 \mathrm{MHz}$ and a Varian XL-200 at $50 \mathrm{MHz}$, respectively, in deuteriochloroform solutions with hexamethyldisiloxane (HMDS) as the reference. X-Ray diffraction patterns were recorded with film samples using Nifiltered $\mathrm{Cu}-K \alpha$ radiation on a Rigaku-Denki RAD II diffractometer. Film samples were obtained by casting from the polymer solutions in tetrahydrofuran on slide glass. Differential scanning calorimetry (DSC) was determined on a Rigaku-Denki Thermoflex provided with a low temperature unit. About a $2 \mathrm{mg}$ sample was taken $\left(20 \mathrm{mg}\right.$ for $\mathrm{C}_{12}$ polymers) in an aluminum pan covered with a lid. Both the heating and cooling rates were $5^{\circ} \mathrm{C} \mathrm{min}-1$ throughout. Gel-permeation chromatography was run on a Toyo-Soda HLC-802UR with two 2-ft GMH columns in tetrahydrofuran. The columns were calibrated with a set of linear narrow molecular weight polystyrenes.

\section{RESULTS AND DISCUSSION}

\section{Characterization of the Copolymer Structure}

Table I shows the yields and molecular weights of the copolymer I, II, and homopolymer III samples used in the DSC study. The molecular weight distributions were polydisperse and the molecular weights were estimated from the gel-permeation chromatogram peak tops. An example is shown in Figure 2.

Figures 3 and 4 show the IR and ${ }^{1} \mathrm{H}$ NMR spectra of the alternating butadiene-octadecyl methacrylate copolymer (copolymer $\mathbf{I}-\mathrm{C}_{18}$ ), its hydrogenated copolymer (copolymer II-C ${ }_{18}$ ), and poly(octadecyl methacrylate) (homopolymer III-
Table I. Synthesis of comb-like polymers

\begin{tabular}{|c|c|c|}
\hline \multirow{2}{*}{ Polymer } & \multirow{2}{*}{$\frac{\text { Yield }}{\%}$} & \multirow{2}{*}{$\frac{\text { Molecular weight }^{\mathrm{a}}}{\times 10^{-4}}$} \\
\hline & & \\
\hline I $-\mathrm{C}_{12}$ & 68 & $\mathrm{c}$ \\
\hline II- $\mathrm{C}_{12}$ & $\mathrm{~b}$ & 4 \\
\hline III- $\mathrm{C}_{12}$ & 63 & 30 \\
\hline I- $\mathrm{C}_{14}$ & 52 & $\mathrm{c}$ \\
\hline II- $\mathrm{C}_{14}$ & $\mathrm{~b}$ & 9 \\
\hline III- $\mathrm{C}_{14}$ & 65 & 30 \\
\hline $\mathrm{I}-\mathrm{C}_{16}$ & 29 & $\mathrm{c}$ \\
\hline II- $\mathrm{C}_{16}$ & $\mathrm{~b}$ & 30 \\
\hline III- $\mathrm{C}_{16}$ & 88 & 9 \\
\hline $\mathrm{I}-\mathrm{C}_{18}$ & 21 & $\mathrm{c}$ \\
\hline II- $\mathrm{C}_{18}$ & $\mathrm{~b}$ & 50 \\
\hline III-C $\mathrm{C}_{18}$ & 72 & 60 \\
\hline
\end{tabular}

a By GPC peak tops.

b Quantitative.

c Not determined.

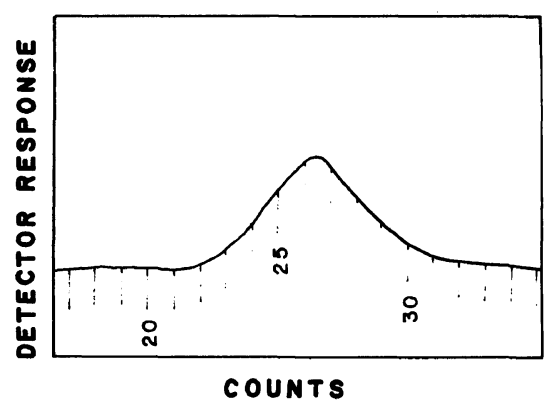

Figure 2. GPC chromatogram of hydrogenated alternating butadiene-octadecyl methacrylate copolymer II$\mathrm{C}_{18}$. A differential refractometer detector was used.

$\mathrm{C}_{18}$ ). Other polymers having $\mathrm{C}_{12}-\mathrm{C}_{16}$ alkyl side chains showed essentially the same spectra as these, because of the trivial difference in the number of carbon atoms in the side chains.

The alternating structure of copolymers I and hence the periodic structure of copolymers $\mathbf{I I}^{11}$ could be confirmed by the following facts. (1) In the ${ }^{1} \mathrm{H}$ NMR spectra of copolymers I, the peak intensity ratios of the $\alpha-\mathrm{CH}_{2}$ of alkyl side chains in methacrylate units $(4.00 \mathrm{ppm})$ to the $-\mathrm{CH}=\mathrm{CH}-$ of butadiene units $(5.30 \mathrm{ppm})$ were approximately $1: 1$; this was the case for all the copolymers obtained from experiments with various monomer feed ratios. (2) All of the various alternating butadienemethacrylate ester copolymers synthesized in our 


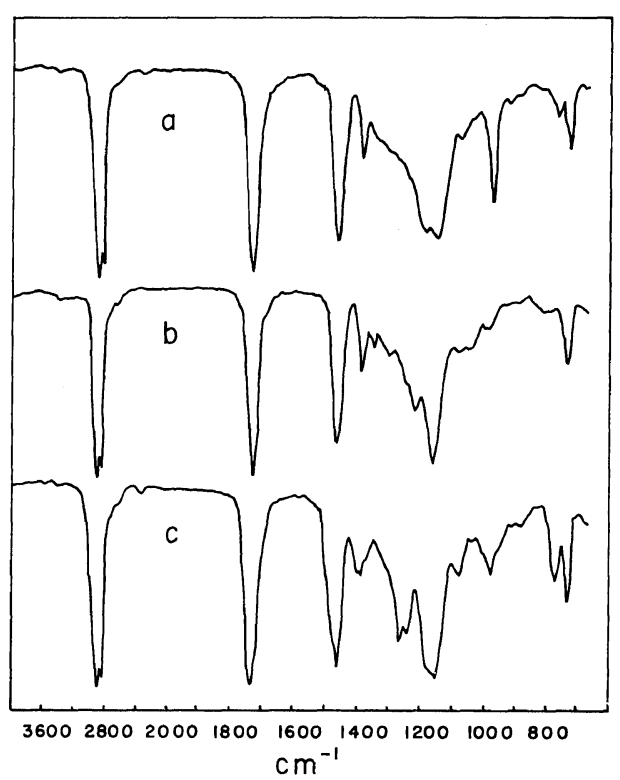

Figure 3. IR spectra of (a) alternating butadieneoctadecyl methacrylate copolymer $\mathrm{I}-\mathrm{C}_{18}$, (b) its hydrogenated copolymer II- $\mathrm{C}_{18}$, and (c) poly(octadecyl methacrylate) III- $\mathrm{C}_{18}$. Spectra were taken for films cast on rock salt plates.

previous paper ${ }^{12}$ were found to have the proposed structures on the basis of $a^{13} \mathrm{C}$ NMR study of their hydrogenated copolymers. (3) The proton noise decoupled and INEPT (Intensive Nuclear Enhancement through Polarization Transfer ${ }^{13}$ ) ${ }^{13} \mathrm{C}$ spectra of $\mathrm{II}-\mathrm{C}_{18}$ in Figure 5 along with data in Table II summarizing the ${ }^{13} \mathrm{C}$ chemical shifts of the skeletal carbon atoms of various hydrogenated butadiene-methacrylate ester copolymers make it possible to assign several peaks to the skeletal carbon atoms of II-C $\mathrm{C}_{\mathbf{1 8}}$, as shown in Figure 5. These peaks are so sharp and single that they indicate a high sequential purity of the hydrogenated copolymer and hence the parent alternating copolymer.

Thus we have two types of widely-spaced comblike polymers, I and II, and conventional comb-like polymers, III, with $\mathrm{C}_{12}, \mathrm{C}_{14}, \mathrm{C}_{16}$, and $\mathrm{C}_{18}$ alkyl side chains.

DSC Curves of Conventional Comb-Like and Widely-Spaced Comb-Like Polymers

At first, the DSC measurement was carried out using a heating mode. While homopolymers III showed single endothermic melting peaks at the

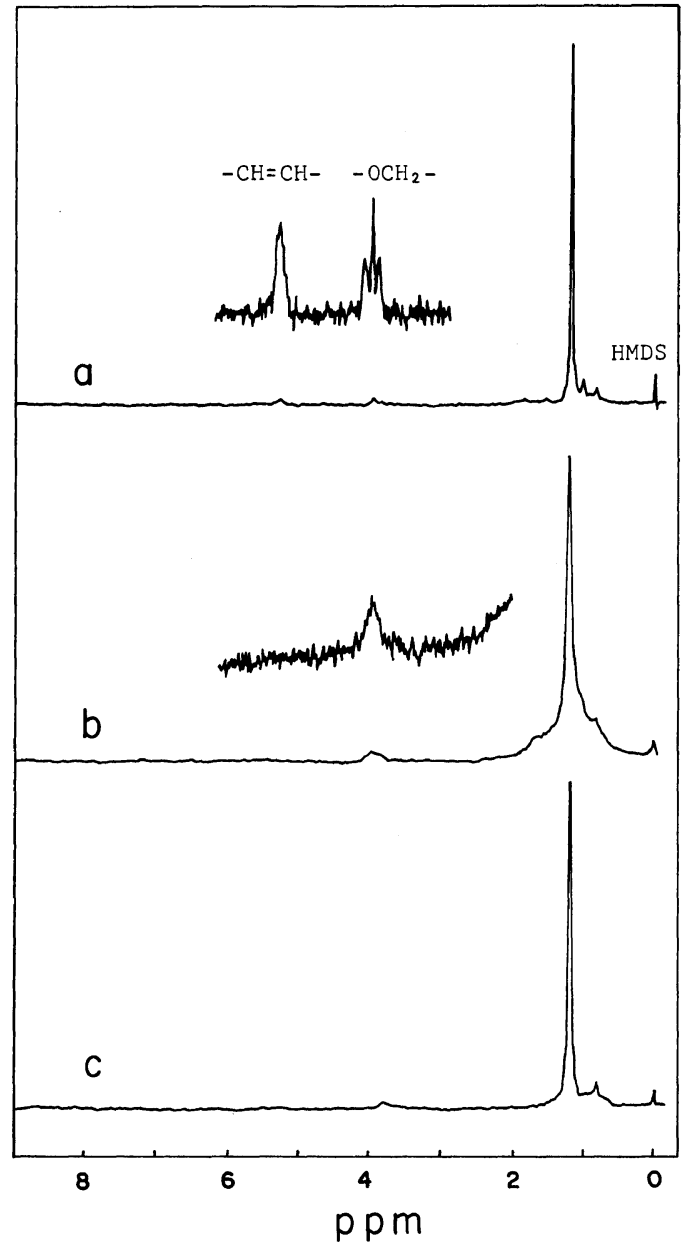

Figure 4. ${ }^{1} \mathrm{H}$ NMR spectra of (a) alternating butadiene-octadecyl methacrylate copolymer I-C $\mathrm{C}_{18}$, (b) its hydrogenated copolymer II- $\mathrm{C}_{18}$, and (c) poly(octadecyl methacrylate) III- $\mathrm{C}_{18}$. Spectra were obtained at $60 \mathrm{MHz}$ in deuterochloroform with HMDS as a reference.

temperatures reported in the literature ${ }^{3}$ copolymers I and II generally showed two melting peaks. This is probably due to crystal reorganization during the heating process. Therefore, studies were carried out using a cooling mode.

A sample was first heated to and maintained for 5 min at about 30 degrees higher than its melting temperature. The cooling DSC curve was then recorded. Single exothermic freezing peaks were observed for all polymers at temperatures several degrees lower than the corresponding melting 
Synthesis, Structure, and Thermal Properties of Polymers

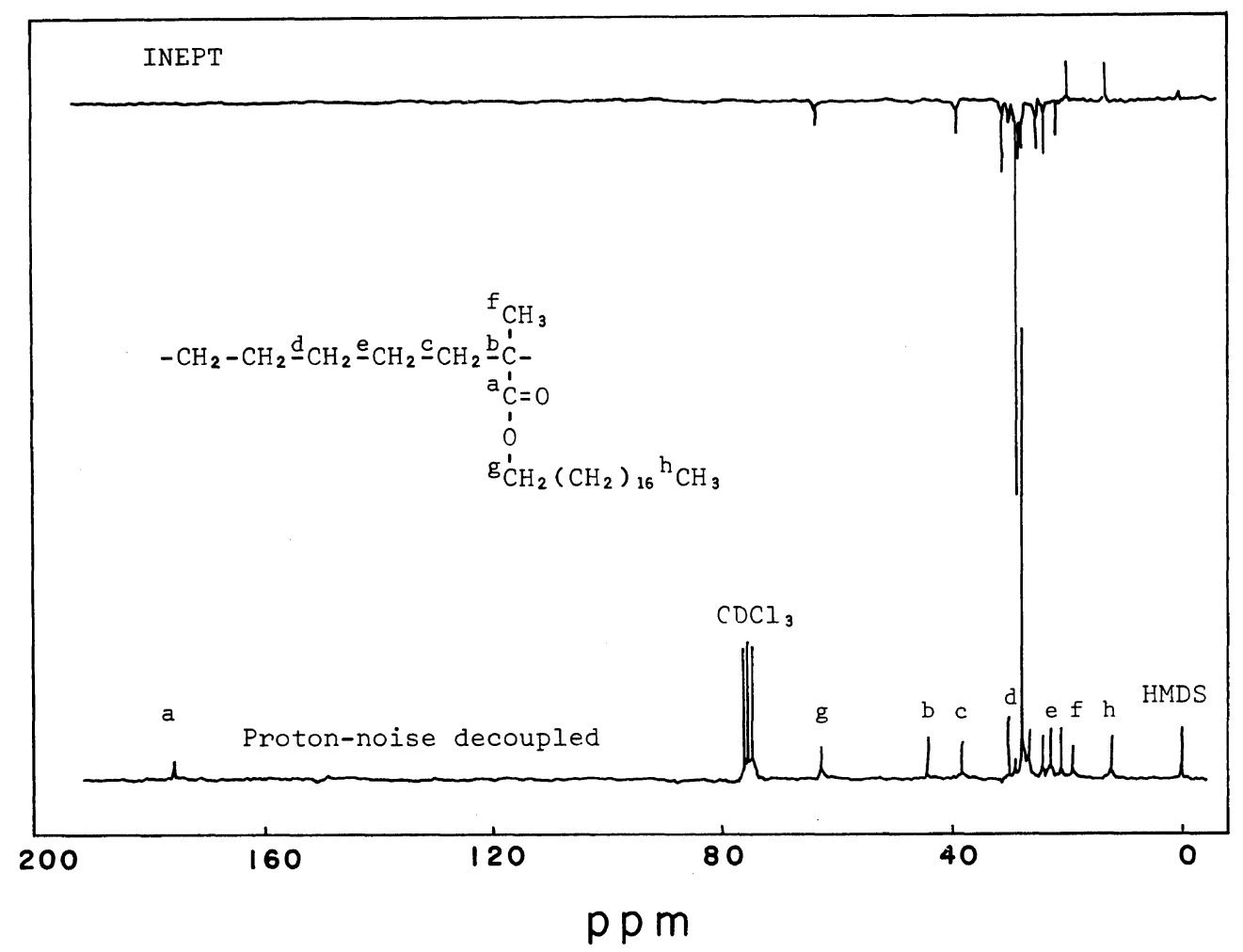

Figure 5. Proton noise decoupled and INEPT ${ }^{13} \mathrm{C}$ spectra of the hydrogenated butadiene-octadecyl methacrylated copolymer II. Spectra were obtained at $50 \mathrm{MHz}$ in deuterochloroform with HMDS as a reference. The INEPT spectrum shifted slightly downfield for better illustration.

Table II. ${ }^{13} \mathrm{C}$ NMR Chemical shift of the skeletal carbons of various hydrogenated butadiene-methacrylate esters copolymers,<smiles>[R]OC(=O)C(C)(C)CCCCC</smiles>

ppm from HMDS

\begin{tabular}{|c|c|c|c|c|c|c|c|}
\hline & $\mathbf{R}$ & ${ }^{\mathrm{a}} \mathrm{C}$ & ${ }^{\mathrm{b}} \mathrm{C}$ & ${ }^{\mathrm{c}} \mathrm{C}$ & ${ }^{\mathrm{d}} \mathrm{C}$ & ${ }^{\mathrm{e}} \mathrm{C}$ & ${ }^{\mathrm{f}} \mathrm{C}$ \\
\hline & Methyl & 176.31 & 44.04 & 37.60 & 28.71 & 22.56 & 19.19 \\
\hline & Ethyl & 175.52 & 43.86 & 37.56 & 28.77 & 22.53 & 19.10 \\
\hline & Isopropyl & 174.93 & 43.75 & 37.58 & 28.85 & 22.52 & 19.01 \\
\hline & Phenyl & 173.97 & 44.33 & 37.61 & 28.75 & 22.66 & 19.12 \\
\hline & Benzyl & 175.25 & 44.03 & 37.63 & 28.73 & 22.57 & 19.03 \\
\hline \multirow[t]{3}{*}{ - } & ------ & ---- & ---- & -- & -- & -- & -- \\
\hline & Tetradecyl & 175.53 & 44.00 & 37.83 & 28.92 & 22.71 & 19.02 \\
\hline & Octadecyl & 175.51 & 44.00 & 37.86 & 28.93 & 22.72 & 19.01 \\
\hline
\end{tabular}




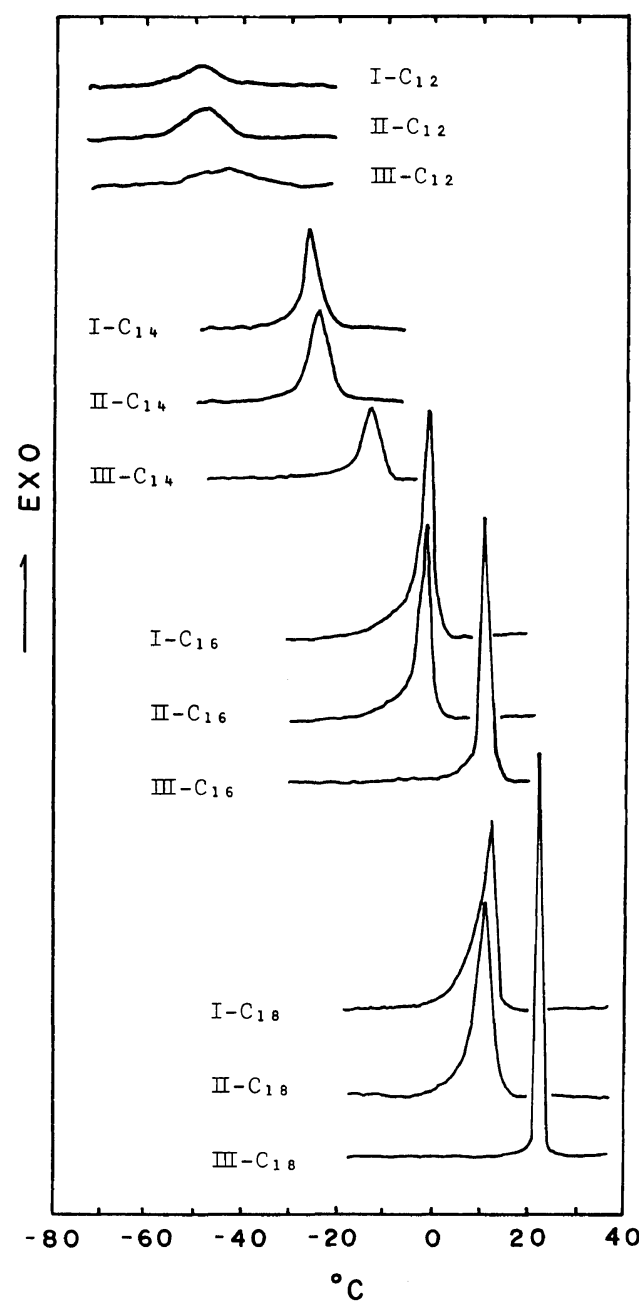

Figure 6. DSC curves for the widely-spaced comb-like polymers I and II and the conventional comb-like polymers III. The cooling rate was $5^{\circ} \mathrm{C} \mathrm{min}-1$.

peaks. (In our previous papers, ${ }^{9,12}$ I and II type polymers with methyl and benzyl ester groups showed melting peaks owing to the periodic structure of thier main chains. But the polymers with ethyl, isopropyl, and phenyl ester groups did not do so in spite of their identified periodic structures. Copolymers I and II in this paper may possibly be of the latter group and showed only single peaks.) The results are compiled in Figure 6. In general, as the number of carbon atoms in the alkyl side chains increases from 12 to 18 , the freezing peaks of copolymers I and II as well as homopolymers III shift to higher temperatures and become sharper

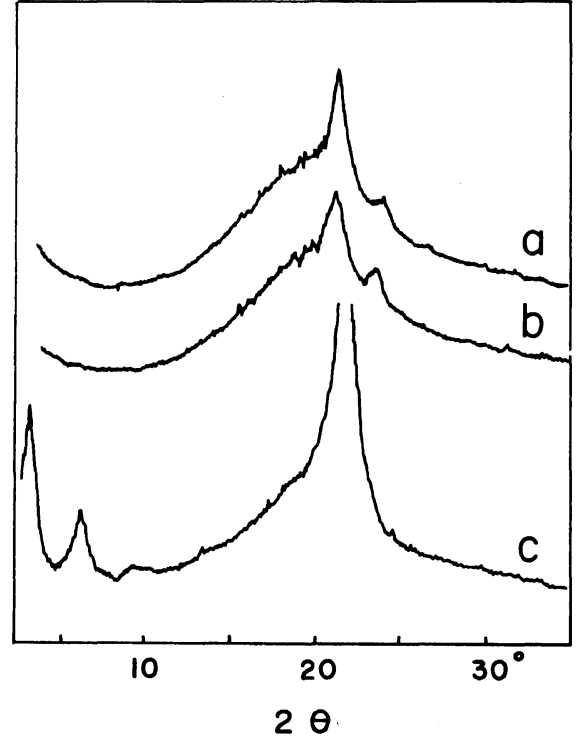

Figure 7. X-Ray diffraction patterns of (a) alternating butadiene-octadecyl methacrylate copolymer $\mathrm{I}-\mathrm{C}_{18}$, (b) its hydrogenated copolymer II- $\mathrm{C}_{18}$, and (c) poly(octadecyl methacrylate) III-C $\mathrm{C}_{18}$.

and stronger. Copolymers I and II showed somewhat broader peaks at lower temperatures than homopolymers III with the same alkyl side chains.

Thus, the long alkyl side chains in the widelyspaced comb-like polymers I and II are considered to crystallize like those of the conventional comblike polymers III in spite of the intervening seven main chain carbon atoms between them. The freezing temperatures, $T_{\mathrm{f}}$, determined from the peak tops, are summarized in Table III.

\section{$X$-Ray Diffraction Patterns}

Figure 7 shows the X-ray diffraction patterns of copolymers I and II and homopolymer III. All samples showed peaks at about $2 \theta=21^{\circ}$, indicating $4.2 \times 10^{-10} \mathrm{~m}$ spacings. On the basis of a detailed study of the conventional comb-like polymers for which good diffraction patterns were obtained, a peculiar layered structure made up of parallel alkyl side chains arranged on both sides of the main chain has been proposed (Figure 8). ${ }^{2}$ In this structure, the spacing between two neighboring alkyl side chains is $4.2 \times 10^{-10} \mathrm{~m}$. For the widely-spaced comb-like polymers I and II, a similar packing of alkyl side chains may be possible. The packing may be like that depicted in Figure 1(b). The conformations of 
Synthesis, Structure, and Thermal Properties of Polymers

Table III. Thermal properties of comb-like polymers

\begin{tabular}{|c|c|c|c|}
\hline Polymer & 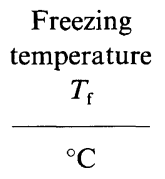 & $\begin{array}{c}\text { Heat of } \\
\text { crystallization } \\
\Delta H_{\mathrm{f}} \\
\text { kcal repeating unit }{ }^{-1} \mathrm{~mol}^{-1}\end{array}$ & $\begin{array}{l}\text { Number of } \\
\text { crystallizing } \\
\mathrm{CH}_{2} \text { group } \\
N\end{array}$ \\
\hline $\begin{array}{l}\text { I- } C_{12} \\
\text { II- } C_{12} \\
\text { III-C } C_{12}\end{array}$ & $\begin{array}{l}-48 \\
-48 \\
-42\end{array}$ & $\begin{array}{l}0.46 \\
0.63 \\
0.38\end{array}$ & $\begin{array}{l}0.6 \\
0.9 \\
0.5\end{array}$ \\
\hline $\begin{array}{l}\text { I- } C_{14} \\
\text { II-C }{ }_{14} \\
\text { III-C } 14\end{array}$ & $\begin{array}{l}-26 \\
-25 \\
-13\end{array}$ & $\begin{array}{l}1.97 \\
2.52 \\
1.40\end{array}$ & $\begin{array}{l}2.7 \\
3.4 \\
1.9\end{array}$ \\
\hline $\begin{array}{l}\text { I- } C_{16} \\
\text { II- } C_{16} \\
\text { III- } C_{16}\end{array}$ & $\begin{array}{r}-1 \\
-\quad 2 \\
11\end{array}$ & $\begin{array}{l}3.96 \\
4.62 \\
2.95\end{array}$ & $\begin{array}{l}5.4 \\
6.3 \\
4.0\end{array}$ \\
\hline $\begin{array}{l}\text { I-C } 18 \\
\text { II-C }{ }_{18} \\
\text { III-C } 18\end{array}$ & $\begin{array}{l}12 \\
12 \\
23\end{array}$ & $\begin{array}{l}5.49 \\
6.01 \\
4.12\end{array}$ & $\begin{array}{l}7.5 \\
8.2 \\
5.6\end{array}$ \\
\hline
\end{tabular}

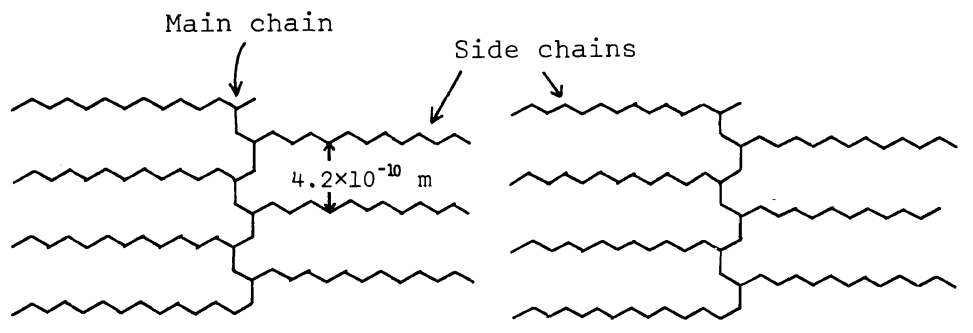

Figure 8. A proposed structure for conventional comb-like polymers. ${ }^{2}$

the main chains should be modified to a small extent so as to accommodate the above spacings.

\section{IR Spectra in the $720 \mathrm{~cm}^{-1}$ Region}

Chapman ${ }^{14}$ pointed out the correlation between the appearance of bands associated with the $\mathrm{CH}_{2}$ rocking mode in the $720 \mathrm{~cm}^{-1}$ region of the IR spectra of crystalline long alkyl chain compounds and the type of alkyl chain packing. Compounds showing two peaks at 727 and $719 \mathrm{~cm}^{-1}$ are of the orthorhombic type packing and those showing a single bands at $720 \mathrm{~cm}^{-1}$ are of the hexagonal type packing. Shibaev et al. ${ }^{15}$ showed that homopolymers III as well as poly(alkyl acrylates), poly(alkyl vinyl ethers), and poly(vinyl alkanoates) all crystallized in hexagonal packing (in accordance with Xray studies) as characterized by a single absorption band at $720 \mathrm{~cm}^{-1}$. In Figure 3 copolymers I and II show single bands at $720 \mathrm{~cm}^{-1}$, indicating that their long alkyl side chains are of the hexagonal type packing and certainly not of the orthorhombic type packing.

\section{Number of Crystallizing $\mathrm{CH}_{2}$ Groups}

Table III also shows the heats of crystallization, $\Delta H_{\mathrm{f}}$, estimated from the DSC peak areas, and the number of crystallizing $\mathrm{CH}_{2}$ groups in the side chains, $N$, for copolymers I and II and homopolymers III. The quantity, $N$, was calculated by dividing $\Delta H_{\mathrm{f}}$ by the heat of fusion per $\mathrm{CH}_{2}$ of $n$-alkanes in the hexagonal packing $(735 \mathrm{cal}$ $\left.\mathrm{CH}_{2}{ }^{-1} \mathrm{~mol}^{-116}\right)$. No correction was made for any contribution from the end groups.

As shown in Figure 9, the $N$ values increase as the number of carbon atoms in the side chains increase for copolymers I and II and homopolymers III. The 


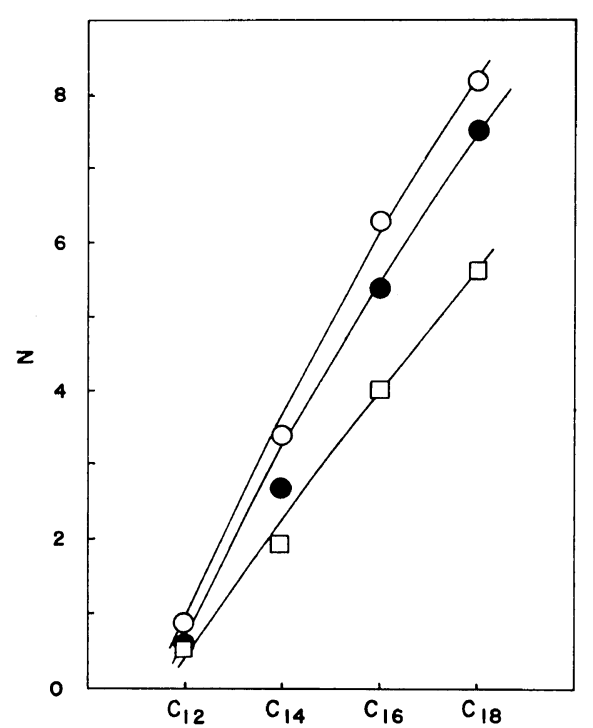

Figure 9. The relationship between the number of crystallizing $\mathrm{CH}_{2}$ groups, $N$, and the length of alkyl side chain. Filled circles, copolymers I; open circles, copolymers II; and squares, homopolymers III.

$N$ values for copolymers I and II are similar and somewhat larger than those for the corresponding homopolymers III. That is to say, in spite of intervening seven carbon atoms in the main chain, the alkyl side chains of widely-spaced comb-like polymers can crystallize to a greater extent than conventional comb-like polymers. This is because the main chains of copolymers I and II are more flexible than those of homopolymer III, as suggested by their tensile properties ${ }^{12}$ and allow the side chains to come closer to each other and crystallize. However, though the total number of crystallizing $\mathrm{CH}_{2}$ groups is somewhat larger for widely-spaced comb-like polymers, the length of crystallizing $\mathrm{CH}_{2}$ groups is not uniform and broad peaks are observed in Figure 6. The lower $T_{\mathrm{f}}$ values for I and II than that for III as shown in Figure 6 and Table III may result from the larger entropy of melting for $I$ and II. In the melt phase, the alkyl side chains of I and II can move more freely than those of III, because of the wider spaces.

\section{Conclusions}

Two types of widely-spaced comb-like polymers whose long alkyl side chains appear on every six main chain carbon atoms were synthesized and characterized. A DSC study revealed that the alkyl side chains can crystallize as in the case of conventional comb-like polymers.

Acknowledgement. The authors wish to thank Mrs. M. Aoyama for her assistance in the preparation of this manuscript.

\section{REFERENCES AND NOTES}

1. Macromolecules with irregularly branched long side chains often are also denoted as comb-like polymers.

2. N. A. Platé and V. P. Shibaev, J. Polym. Sci., Macromol. Rev., 8, 117 (1974).

3. S. A. Greenberg and T. Alfrey, J. Am. Chem. Soc., 76, 6280 (1954).

4. A. Turner-Jones, Makromol. Chem., 71, 1 (1964).

5. J. Lal and G. S. Trick, J. Polym. Sci., A, 2, 4559 (1964).

6. E. F. Jordan, Jr., D. W. Feldeisen, and A. N. Wrigley, J. Polym. Sci., A-1, 9, 1835 (1971).

7. C. G. Overberger, C. Franzier, J. Mandelman, and H. F. Smith, J. Am. Chem. Soc., 75, 3326 (1953).

8. C. G. Overberger, L. H. Arond, R. H. Wiley, and R. R. Garrett, J. Polym. Sci., 7, 431 (1951).

9. K. Yokota and T. Hirabayashi, Macromolecules, 14, 1613 (1981).

10. L. A. Mango and R. W. Lenz, Makromol. Chem., 163, 13 (1973).

11. In our previous papers,,${ }^{9,12}$ we regarded these copolymers as having periodic ethylene-ethylenemethacrylate sequences.

12. K. Yokota, T. Kougo, and T. Hirabayashi, Polym. J., 15, 349 (1983).

13. G. A. Morris and R. Freeman, J. Am. Chem. Soc., 101, 761 (1979).

14. D. Chapman, J. Chem. Soc., 4489 (1957).

15. V. P. Shibaev, B. S. Petrukhin, Yu. A. Zubov, N. A. Platé, and V. A. Kargin, Vysokomol. Soedin., A, 10, 216 (1968).

16. M. G. Broadhurst, J. Res. Natl. Bur. Stand., 66A, 241 (1962). 